\title{
The Image of Death in Don DeLillo's Later Works
}

\author{
Chi-Min Chang
}

\begin{abstract}
The image of death in Don DeLillo's later works, transcending the commonly-held assumptions, features affect. They epitomize the forces driving toward new thinking and ideas not yet construed. The acute perception of these images is marked by the rupture with the presupposed logical or causal connections. Second, the affect of the death-related image underscores the body and renews one's perception of relation between life and death, reality and fiction, and even the self and the other. The images of death foregrounds affect, reconfiguring the ethical. The study will apply Brian Massumi's affect to examine how the image of death, mediated or otherwise, designates alternative ethical possibilities.
\end{abstract}

Index Terms-Affect, death, DeLillo, image.

\section{INTRODUCTION}

Death has been constantly blended in DeLillo's works in chronicling contemporary American life, from the protagonists' obsessive fear towards death in White Noise, the death of a seclusive writer in Mao II, Kennedy's assassination in Libra, and the cultic murder in The Names to the (im)mediated image of death in Underworld, Falling Man, Cosmopolis, and Point Omega. Death in earlier works has been mostly presented as daily fear or terror coming from a horrifying future possibility or the past actuality - a void in the present. It is an absent Other which transcends one's understanding but impinges on the certainty of selfhood. The confrontation with death is an inevitable obsession and struggle which one's life is inevitably pivoted at. However, in later works, death tends to be presented as a concrete image, mediated or otherwise. What is worth noting is that DeLillo's image of death features both affect and an ethical exploration. It is an intriguing imaging going beyond general presumptions or suppositions. The image of death, rid of the commonly-recognizable framework of association and designation, bases itself on different modality of intensity, designating a bundle of potential ideas or possibilities. Its propensity to evoke new ideas is obvious while the presumptions concerning life and death, self and other, fiction and reality, are defied. These alternative images of death marks the descriptive and the incipient of his writing in later works.

DeLillo's intriguing image in later works has caught much attention among the critics. Some assume that DeLillo incorporates the aesthetic ideas in the first half of $20^{\text {th }}$ century; some take it as the consequence of his literary innovation to catch the not-yet-described reality. Philip Nel remarks that, by putting together disparate images, "DeLillo keeps returning to the ambiguous legacy of avant-garde as a way of imagining a resistance to the forces in which his characters

Manuscript received May 15, 2015; revised September 14, 2015.

Chi-Min Chang is with the Department of English Instruction, University of Taipei, Taiwan, 10048, R.O.C. (e-mail: fionachang@utaipei.edu.tw). find themselves enmeshed" [1]. Take the juxtaposition of two blasts in Underworld for example. On the New York Times of 4 October, 1951, was a dual headline in which the left side displayed Bobby Thompson's homerun and the right side was an announcement of Russian atomic bomb. The striking contrast like this does confront the reader with the co-existence of the incompatible. It is true indeed that such contrasting image does cause great disturbance in idea-association or meaning-making.

However, that may not be the only effect. More images demonstrate that DeLillo means to arouse our awareness of those aspects of life which otherwise can be unknown or unconceivable. It reminds us of a situation that that Frederic Jameson commented - “[w]e do not yet process the perceptual equipment to which match this new hyperspace... because our perceptual habits were formed in that older kind of space I have called the space of high modernism" [1]. According to DeLillo in an interview with Alexandra Alter, "[w]riters, some of us, may tend to see things before other people do, things that are right there but aren't noticed in the way that a writer might notice" [2]. But, how exactly is DeLillo's image of death help catch the uncharted domain of reality? The idea may be uncertain as the new mechanism is not yet there for us to approach the reality we are having. Another worth-noting feature is how the stimulating and provocative image is foregrounded. That is what Robert Chodat considers about DeLillo's writing. It is "aesthetically innovative and provocative.... [They] challenge our pre-reflective ways with words. They are texts that imagine alternative languages in order to imagine alternative forms of life" [3]. But, how exactly does DeLillo manipulate the aesthetic skills to convey his ideas to catch the potential or alternative dimensions of life and alter the writing style? More significantly, how or based on what these different dimensions of life are construed?

\section{IMAGE OF DEATH VS. AFFECT}

The inexplicable but perceivable effect of the image of death in DeLillo's writing can be understood in the light of Brian Massumi's idea of affect. Massumi remarks that the image reception works at least on bi-level-the content and the effect. The content means the conventional meaning in socio-linguistic context. More specifically, the content refers to the semantic or semiotic which designates the signifying system or ideological framework. Yet, "the strength or duration of the image's effect could be called its intensity" [4]. The intensity refers to the effect brought about by the image. The intensity is usually something that exceeds the social or semantic framework in the image. The idea of affect corresponds to DeLillo's image of death. Delillo's image has a conspicuous target and content and features a distinct effect transcending what are socially or linguistically recognizable. 
That is what Massumi contends, "the primacy of the affective is marked by a gap between content and effect" [4]. The image reception simultaneously works on the semantic or semiotic mechanism and the intensity. More importantly, intensity is "outside expectation and adaptation, as disconnected from meaningful sequencing, from narration.... It is narratively delocalized, spreading over the generalized body surface... "[4]. For one thing, the intensity of image usually exceeds the narration or the description. For another, it has its effect on the body and evokes the sensuous reaction. The effect, perceived and unrecognizable, is where the image reception is channeled into new routes of thinking and conception. For the following analysis, I would like to apply the intensity of Massumi's affect from two perspectives. Generally speaking, the presentation of the images of death in DeLillo's later works fall into two categories, mediated and the empirically experienced. For the mediated image of death, I will particularly focus on its feature of being beyond expectation and adaptation. For the empirical experience, the argument will stress on the intensity or effect on the body.

\section{The Mediated IMAge OF DEATH}

The image of death in DeLillo's later writing foregrounds the intensity of affect, as the unexpected, asignifying, and incompatible, the incipient. Most of all, it is unidentifiable but concretely felt. The mediated image of death in Underworld is deliberately inserted in a seemingly irrelevant narrative and hence makes a stark contrast. The novel opens with an exhilarating scene of the audience's celebrating Thompson's homerun in Polo Grounds in 1953 but the image is juxtaposed with the image of death which is abrupt and unassimilable to the main narrative. That is the reproduction of Pieter Bruegel's Triumph of Death ${ }^{1}$, torn from the Life Magazine as paper shreds and thrown from the bleachers to the baseball field and the players [5]. With the common assumptions or ideas overturned, the image re-channels one's understanding into an alternative perception. The perception reveals the effect of the image which does not correspond to an understandable concept or idea. Marco Abel in Violent Affect: Literature, Cinema and Critique after Representation contends that it is the image of sensation instead of that of imagination, drawing on Deleuze's comment on the recurring motif of screaming in the paintings of Francis Bacon (28 October 1909-28 April 1992). It is "to paint the scream instead of the horror." That is, "Bacon is more interested in painting the affect that sustains the intensity of violence than the cause (horror) that produced the effect (the scream) [6]. This kind of image does not follow the causal relationship. It is open-ended in meaning and interpretation, stressing the force or effect by means of the asignifying intensity. Besides, by dint of the ballgame between the Giants and the Dodgers, DeLillo presents multiple facets of American life, from the individual to the crowd, from baseball to real life, from entertainment to the U.S.-Soviet political relation, and from

${ }^{1}$ The Triumph of Death is an oil painting by Pieter Bruegel the Elder in 1562. "In this setting, legions of skeletons advance on the living, who either flee in terror or try in vain to fight back. In the background, skeletons haul a wagon full of skulls; in the upper left corner, others ring the bell that signifies the death knell of the world" (NP, Wikipedia). There is similar detailed description of the painting in the novel, too. the broadcaster to the spectators. Baseball in a sense epitomizes the entanglement of various dimensions of American life. The entanglement is amazingly done by DeLillo's foregrounding the paper-tossing custom in watching baseball game. It is a way for people to express their feeling or formulate some connection with momentous moments or players they especially enjoy. During the game, the paper kept falling. On the paper shreds are "[b]aby food, instant coffee, encyclopedias and cars, waffle irons and shampoos and blended whiskeys" [7]. Different aspects of life have been presented, incorporated, and condensed in the scene of the baseball game. The game actually acted as a panoramic presentation of American life. However, in addition to presenting the kaleidoscopic American life, what is particularly striking is still how Thompson's homerun is interpolated by and juxtaposed with Bruegel's The Triumph of Death and the Soviet Union's test of the atomic bomb. The incongruous image takes place when the character J. Edgar Hoover watching the ballgame got a piece of paper, torn from Life Magazine thrown from the upper deck. On the piece of the paper is The Triumph of Death. It is a scene of the dead taking over the living - an army of skeleton, legions of the dead, the violent scenes of a gaunt dog nibbling a baby in a dead woman's arm, a woman straggled by a skeleton, etc.

The horrifying scene of death in a desolate landscape reminded Edgar of a nuclear test site. More specifically, he thought about the atomic test that the Soviet Union conducted. The epochal moment is a contrast between a ballgame and the cold war period, fiction and reality, life and death, embroidered by different facets of everyday life and feelings. Bobby Thompson's homerun is more than a sharp contrast with Bruegel's painting or Russia's bomb test. It is extended and blended with the spectators' interaction with each other, involving other social dimensions such as the character Cottor Martin, the black boy who got Thompson's ball in the novel. While the colored vendor walked among the spectators, it acutely reminded him of his difference as well as the inferior social position, "making him visible, shaming him in his prowler's den" [7]. Another aspect of the situation is the reflection of the broadcaster, Russ Hodges, about how he manipulated the audience. He said, "[s]omebody hands you a piece of paper filled with letters and numbers and you have to make a ball game out of it" [7]. It talks about the game made up in the ballgame, the fiction folded in the fiction. All of these, as shreds of paper tossing down the baseball field, are coming along with the Giants' winning the pennant. This makes it all the more difficult to figure out what the image of death designates while the exhilaration for the homerun was embroidered by the bewildering and variegated scene of American life and the Soviet Union's unclear bomb. It does not render a thematic clarity. Neither can it be said to be a random pastiche of irrelevant aspects of life.

The image of death arouses the reader's awareness of the various aspects of the event and blurs the distinction between fiction and reality, life and death, self and other. It generates an alternative aspect and perception of reality as death folded in life, happiness in death, black in white, fiction in reality. Erasing the distinction indicates that life is made up of constant encounter and connection. More importantly, death is presented as part of day-to-day life, strikingly attached to 
the exhilarating social event. As Bruegel's painting reflects, the army of death, as those who made the atomic bomb in Russia, do their work in real life and aim at taking everyone's life, including women and children, making a desolate and bleak world.

Another example is in Point Omega. Death is displayed in Douglas Gordon's 24 Hour Psycho with an anonymous viewer immersing himself in watching the scene of the murder. The reframed video, silenced and slowed to 24 hours, overturns what we used to know about the movie, Psycho, directed by Alfred Hitchcock. It arouses different perception of the movie, the museum, and even the self. As Massumi maintains, "[E]mergence... is a two-sided coin: one side in the virtual (the autonomy of the relation), the other in the actual (functional limitation).... affect... is precisely this two-sideness, the simultaneous participation of the virtual in the actual and the actual in the virtual as one arises from and returns to the other" [4]. Affect is not a static state but a dynamic relation between possibilities and pre-assumptions. The actual and the virtual are in a back-and-forth relation, feeding back to each other. The video, in a sense, actualizes the virtual, the potential of image reception. The mediated image of death renews one's feeling towards the reality and the self. In the epilogue and coda of Point Omega is an anonymous man watching Douglas Gordon's 24 Hour Psycho. While the video is slowed to a running time of 24 hours, time becomes the major factor dissipating the original association and feeling.

The novel presents the most well-known scene in which the heroine was killed while taking a shower. The image of the heroine's staring at the audience in horror is followed by the image of the blood dissolving in water and flowing into the drain of the bathtub. However, the unknown viewer was not seized by the suspense and fear of the killing. Instead, he was given the "time" to absorb the details he failed to notice at the normal speed, for example, the number of the curtain rings, the actor's eyes, and the relation between the actors' real names and those in the movie. The man found that " $[\mathrm{t}] \mathrm{he}$ less there was to see, the harder he looked, the more he saw" [8]. The constructed meanings of the movie is pulverized as time reconfigures his relation to everything. Watching the scene of the murder, the unknown man was simultaneously pondering over his relationship with the guard, the fellow spectators, and the physical condition. Hence, the narration of the murder in 24 Hour Psycho is interpolated by the man's feeling toward the other spectators and things in real physical context. It "engage[s] the individual at a depth beyond the usual assumptions, the things he supposes and presumes and taken for granted" [8].

The video becomes open-ended in interpretation with the original meaning eradicated. It is "like everything else, outside all categories, open to entry" [8]. The virtual of affect is actualized and juxtaposed with the actual, the original movie. This is what Point Omega has in common with that in Underworld. The only difference is the former foregrounds how the image of death interferes or un-linearizes the main narrative and designates an alternative perception of life. In Point Omega, it goes towards the opposite by suspending or diluting the original fear towards death, marking the virtual dimension of the affect.

\section{THE EMPIRICAL IMAGE OF DEATH}

The other kind of image of death in DeLillo's later works is the empirically experienced. The effect of the image on the body is particularly obvious. However, the body, according to Massumi, does not merely react to the stimulations; "it infolds contexts, it infolds volitions and cognitions that are nothing if not situated" [4]. The infolding will automatically activated the past actions and contexts that were conserved but not yet completed. That is, the infolding will make possible the actualization of the virtual in affect. That is why Massumi remarks, "[i]ntensity is incipience, incipient action and expression", regarding the intensity of affect as a bundle of possibly emergent possibilities. The body, to him, "is a realm of potential.... where futurality combines, unmediated with pastness, where outsides are infolded..." [4]. The incipient of the affect makes a lived paradox in which the normally opposites coexist, coalesce, and connect. It is something unable to be experienced will be felt [4]. Such an idea of affect is further elaborated by Gregory J. Seigworth and Melissa Gregg. First of all, they maintain that affect is the "visceral forces beneath, alongside, or generally other than conscious knowing, vital forces insisting beyond emotion - that can serve to drive us toward movement, toward thought and extension..." [9]. Affect is not the presumed concepts or personal emotions but a force driving us toward new actions or thoughts by dint of the body. The forces come from life confrontations - that is, how the body is impinged upon and evokes the not-yet-thoughts. Seigworth and Gregg add that "[a]ffect makes a body's belonging to a world of encounters or; a world's belonging to a body of encounters." Affect is regarded as the potential power of the body - "a body's capacity to affect and to be affected" [9]. In Cosmopolis, before the multi-billionaire asset manager, Eric Packer, was murdered, he ran into and participated in a movie-shooting scene in which three hundred naked people played dead on the street, either piled up or just lying desolately barren. Joining the naked crowd, Eric consciously had the indescribable feeling towards death in which he was and was not a part. He was alive but pretended to be dead. "They filled the intersection, lying haphazard positions, some bodies draped over others, some leveled, flattened.... They were a sight to come upon, a city of stunned flesh, the bareness, the bright lights, so many bodies unprotected.... The bodies were blunt facts, naked in the street. Their power was their own, independent of whatever circumstance attended the event" [10]. The bodies in the image of death have the force of their own. It is not what any concept or personal intention can account for. Eric perceived that "it was a curious power... there was something shy and wan in the scene, a little withdrawn.... He found them sad and daring both, and more naked than ever in their lives" [10]. The perception of these attributes forcefully drives the participant, the spectator and even the reader to ponder on the blunt and naked body in pretense of death. Another image of death in Cosmopolis infolds the future in the context of the past, as the present is nowhere situated. The business tycoon, Eric Parker, pre-visioned his death in his watch when he was cornered by a murderer in a room. The future is incorporated in the present and, simultaneously he was actualizing the past of the image. The watch installed with advanced technology enabled him to preview his death. That makes death 
particularly paradoxical, since Eric was simultaneously anticipating and participating death at the spot. It is temporally and spatially bewildering, as the juxtaposition of here and there, now and then. He was in and out of death itself.

Another empirical image of death is embodied by a body artist who kept performing the falling in Falling Man. It seemingly reminded the public of the unforgettable panic and fear in 911. Yet, the intensity of the affect comes from his death at the last jump, deliberately done without any secure measures. The real death at the end goes beyond embodying the dying scene in the 911 event. It is more than an ultimate accusation of the terroristic violence or a radical expression of certain aesthetic faith. Falling Man presents an alternative empirical image of death. It is another demonstration of "the body to affect and to be affected," as the body artist keeps performing the free falling not merely as a way to remind the fear in the 911 terrorists' attack but to evoke the virtual effect of the falling. It is like what Francis Bacon told the art critic, Michel Leiris, "I could not paint Agamemnon, Clytemnestra or Cassandra, as that would have been merely another kind of historical painting.... I tried to create an image of the effect it produced inside me" [11]. The effect comes from the direct encounter with the falling and the perception of what such an act evokes. To the body artist, it might a way to approach the historical event. To the spectators, it might be a means to experience the suspension or threshold between life and death. It is an inevitable and compelling effect as the spectators couldn't help but stop to watch. The falling body asserts the force of its own, more than a simulated launch for death, both to the body artist and the spectators. More stunning is the last fall of the body artist, which was an actual embodiment of death. One of the spectators, Lianne, who looked at the picture of his falling, thought that "[h]eadlong, free fall... this picture burned a hole in her mind and heart, dear God, he was a falling angel and his beauty was horrific... She was the photograph, the photosensitive surface. That nameless body coming down, this was hers to record and absorb" [12]. Her feeling was driven to the unrecognizable sensuous perceptions and her body became a recording surface of the falling man. The self infolds the other, life infolds death. Similar effect falls on her husband, Keith, as life and death were no longer distinct and clear ideas or state to him. It was the feeling he had while seeing a falling figure past his office window, saying "[w]hy am I here instead of there" [12]? After his survival, he tried "to tell himself that he was alive but the idea was too obscure to take hold" [12]. The image of death has the effect on the body, transcending the actual or recognizable concepts. The body has the virtual realized and a different perception of the life/death fold.

\section{CONCLUSION}

The images of death in DeLillo's later works, mediated or empirically experienced, correspond to Massumi's idea of affect. For one thing, they are meant to evoke new possibilities or ideas by presenting the inexplicable or incongruous and exploring the alternative aspects of life perception. For another, highlighting the body, either in imaging or perceiving, reconfigures the ethical relation between life and death, self and other, fiction and reality.

\section{REFERENCES}

[1] P. Nel, The Avant-Garde and American Postmodernity, $1^{\text {st }}$ ed. Jackson: UP of Mississippi, 2002, ch. 4, pp. 101-112.

[2] D. DeLillo and A. Alter. Don DeLillo deconstructed: In an in-person interview. Wall Street Journal. (Jan. 29, 2010). [Online]. Available: http://online.wsj.com/articles/SB100014240527487039062045750270 9420891403>

[3] R. Chodat, Worldly Acts and Sentient Things: The Persistence of Agency from Stein to DeLillo, ${ }^{\text {st }}$ ed, Ithaca: Cornell UP, 2008, p. 18.

[4] B. Massumi, "The autonomy of affect," Cultural Critique, vol. 31, pp. 84-96, Autumn 1995.

[5] P. Bruegel. The triumph of death. [Online]. Available: http://en.wikipedia.org/wiki/The_Triumph_of_Death

[6] M. Abel, Violent Affect: Literature, Cinema and Critique after Representation, $1^{\text {st }}$ ed, Lincoln and London: U of Nebraska, 2007, ch. 1, p. 5, 2007.

[7] D. DeLillo, Underworld, New York: Scribner, 1997, pp. 20-39.

[8] D. DeLillo, Point Omega, New York: Scribner, 2010, pp. 5-102

[9] G. J. Seigworth and M. Gregg, "An inventory of shimmers," in The Affect Theory Reader, M. Gregg, Ed. Durham and London: Duke UP, 2010, pp. 1-2.

[10] D. DeLillo, Cosmopolis, New York: Scribner, 2003, pp. 172-73.

[11] F. Bacon. Three studies for figures at the base of a crucifixion on the triptyph. [Online]. Available: http://en.wikipedia.org/wiki/Three_Studies_for_Figures_at_the_Base _of_a_Crucifixion\#The_triptych

[12] D. DeLillo, Falling Man, New York: Scribner, 2007, p. 6-244.

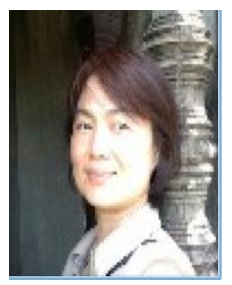

Chi-Min Chang was born in Chai-yi, Taiwan, R.O.C. in 1968. She earned the bachelor's degree, the master's degree, and the doctoral degree in the Department of English in National Taiwan Normal University. Her major in study has been American literature, especially contemporary American fiction.

She had been an English teacher in senior high school for 13 years after graduating from college. It was not until 2008 she started to teach in university. She is an assistant professor now. The papers she published in recent years are "Sensuous Writing in Don DeLillo's Falling Man," NTU Studies in Language and Literature, 2010; "Language as the ethical other: The spatial/temporal loop in The Names," Review of English and American Literature, 2011, "The ethical reconfiguration of the body in Philip Roth's Exit Ghost," TanKang Review, 2012. Another paper to be published this summer is "Liminal space in the city: A study of DeLillo's Falling Man," Wenshan Review of Literature and Culture, 2015. Her research has been focused on the works of Don DeLillo and Philip Roth. While the early phase of the research aims to explore the ethical dimension from the perspective of language, body, and space, the current interest has been shifted to the image, as well as its relation to the ethical and the aesthetic, presented in DeLillo's oeuvre.

Dr. Chang is now the member of the Association of English and American Literature of the Republic of China. 